\title{
Seventh cervical nerve perforating the middle scalene muscle: a possible clinical and surgical application
}

\author{
SILVA, A. T. ${ }^{1 *}$, GAMA, H. V. P. ${ }^{1}$, SIQUEIRA, S. L. ${ }^{2}$, SALES, M. C. ${ }^{3}$, \\ FRANCO, A. G. ${ }^{1}$ and CASAGRANDE, M. M. ${ }^{3}$
}

\begin{abstract}
${ }^{1}$ Acadêmico do $5^{\circ}$ ano de Medicina da Faculdade de Ciências Médicas de Minas Gerais, Monitor da disciplina de Anatomia, Departamento de Anatomia, Faculdade de Ciências Médicas de Minas Gerais - FCMMG, Alameda Ezequiel Dias, 275, Santa Efigênia, CEP 30130-110, Belo Horizonte, MG, Brazil

${ }^{2}$ Pós-doutor em Ciências e Técnicas Nucleares pela Universidade Federal de Minas Gerais - UFMG, Mestre e Doutor em Cirurgia pela UFMG, Professor Assistente da Disciplina de Anatomia da Faculdade de Ciências Médicas de Minas Gerais - FCMMG, Professor Adjunto de Cirurgia da Universidade Federal de Ouro Preto - UFOP, Departamento de Anatomia, Faculdade de Ciências Médicas de Minas Gerais - FCMMG, Alameda Ezequiel Dias, 275, Santa Efigênia, CEP 30130-110, Belo Horizonte, MG, Brazil

${ }^{3}$ Acadêmico do $4^{\circ}$ ano de Medicina da Faculdade de Ciências Médicas de Minas Gerais, Monitor da disciplina de Anatomia, Departamento de Anatomia, Faculdade de Ciências Médicas de Minas Gerais - FCMMG, Alameda Ezequiel Dias, 275, Santa Efigênia, CEP 30130-110, Belo Horizonte, MG, Brazil

*E-mail: adriana.torres.silva@hotmail.com
\end{abstract}

\begin{abstract}
Introduction: In most of cases, the emergency of the nervous roots of the brachial plexus in the posterior cervical triangle occur between the anterior and middle scalene muscles. However, anatomic variations in the brachial plexus are not rare. Methods: In the laboratory of Human Anatomy of the "Faculdade de Ciências Médicas de Minas Gerais" 106 cadavers were dissected. There were dissected the cervical region of all of the cadavers bilaterally. Results: In routinely dissection in the laboratory of human anatomy of the "Faculdade de Ciências Médicas de Minas Gerais" we've found in the left cervical region of a male cadaver the ventral branch of the seventh cervical nerve (C7) perforating the substance of the middle scalene muscle. Conclusion: Professionals that work with this region on the practice must pay attention to this and other variations in the constitution of the brachial plexus in the clinic and surgical procedures to avoid complications.
\end{abstract}

Keywords: brachial plexus, scalene muscles, anatomic variation.

\section{Introduction}

The scalene muscles, that are part of the profound cervical musculature are in the number of three and are called anterior, middle and posterior scalene muscle. They flex the cervical part of the vertebral spine laterally and are also inspiratory muscles (MOORE, DALLEY and AGUR, 2011).

An important anatomic relationship of the scalene muscles is established with the brachial plexus, because of the fact that the nervous roots that form it emerge between the anterior and the middle scalene muscle.

The brachial plexus if formed, in general, by the ventral branches of the inferior cervical nerves (C5, C6, C7, C8) and by the ventral branch of the first thoracic nerve (TI). In its more characteristic arrangement, the ventral branch of C5 is linked to the ventral branch of $\mathrm{C} 6$, forming the superior trunk, the ventral branch of $\mathrm{C} 7$ form the middle trunk and the ventral branch of $\mathrm{C} 8$ is linked to the ventral branch of $\mathrm{Tl}$, forming the inferior trunk. The superior, middle and inferior trunks form the cervical part of the brachial plexus (SKANDALAKIS, SKANDALAKIS and SKANDALAKIS, 2007).

Anatomic variations on the constitution of the brachial plexus are common. However, in this study, we'll concentrate on the variations involving the ventral roots of the cervical nerves and its relationship with the scalene muscles. Despite of the fact that the anatomic variations of the brachial plexus in general not change the normal function of the superior limb, its knowledge and identification is of an extreme importance in the achievement in the realization of orthopedic and neurosurgery interventions in the cervical region (SHETTY, SATHEESHA and MADAHV, 2011).

A lot of authors related in the literature variations of the brachial plexus' formation. The classic description of the plexus, with the $\mathrm{C} 5$ to $\mathrm{Tl}$ nerve roots combining to form three trunks, six divisions, three cords, and five main motor/sensory branches to the upper extremity, is an oversimplification to some degree. In actuality, many variant forms of the brachial plexus exist.

\section{Materials and Methods}

In the laboratory of Human Anatomy of the "Faculdade de Ciências Médicas de Minas Gerais" 106 cadavers were dissected (101 of the male sex and 5 of the female sex), between the years of 1992 and 2011. There were dissected the cervical region of all of the cadavers bilaterally. The method of dissection were: the skin were removed with a median cut in the middle line of the neck, a superior cut in the inferior line of the jaw was made too, and an inferior cut 
on the superior line of the clavicle was made. The platysma was preserved and rebated in the jaw's direction preserving the superficial structures. After, it was made an incision in the superficial cervical fascia in the superior quarto of the sternocleidomastoid muscle and the superficial nerves of the brachial plexus were dissected. The sternocleidomastoid was dissected and rebated with a cut in the middle of the muscle. The extern jugular vein and the cutaneous nerves were cut. The omohyoid muscle was rebated with a cut in its superior venter. After, the fascia of the supraclavicular triangle was removed evidencing the scalene muscles and the trunks of the brachial plexus. A bibliographic review was done with anatomic books and scientific articles indexed in databases like Lilacs, PubMed and BVS. The key words utilized were: brachial plexus, scalene muscles, anatomic variation.

\section{Results}

In our study it was observed the nervous root of C7 perforating the substance of the middle scalene muscle and following in the posterior triangle of the neck to form the middle trunk of the brachial plexus (Figure 1).

Fazan, Amadeus and Caleffi (2003) found the long thoracic nerve perforating the substance of the middle scalene muscle in $63 \%$ of the cases, but there weren't related cases involving C7 and this muscle. However, Accioli and Accioli (2007) found, in their dissections of 12 cadavers, 2 cadavers with all of the nervous roots of the brachial plexus behind the middle scalene scalene muscle. In just one of their cadavers they've found the primary root of $\mathrm{C} 7$ behind the

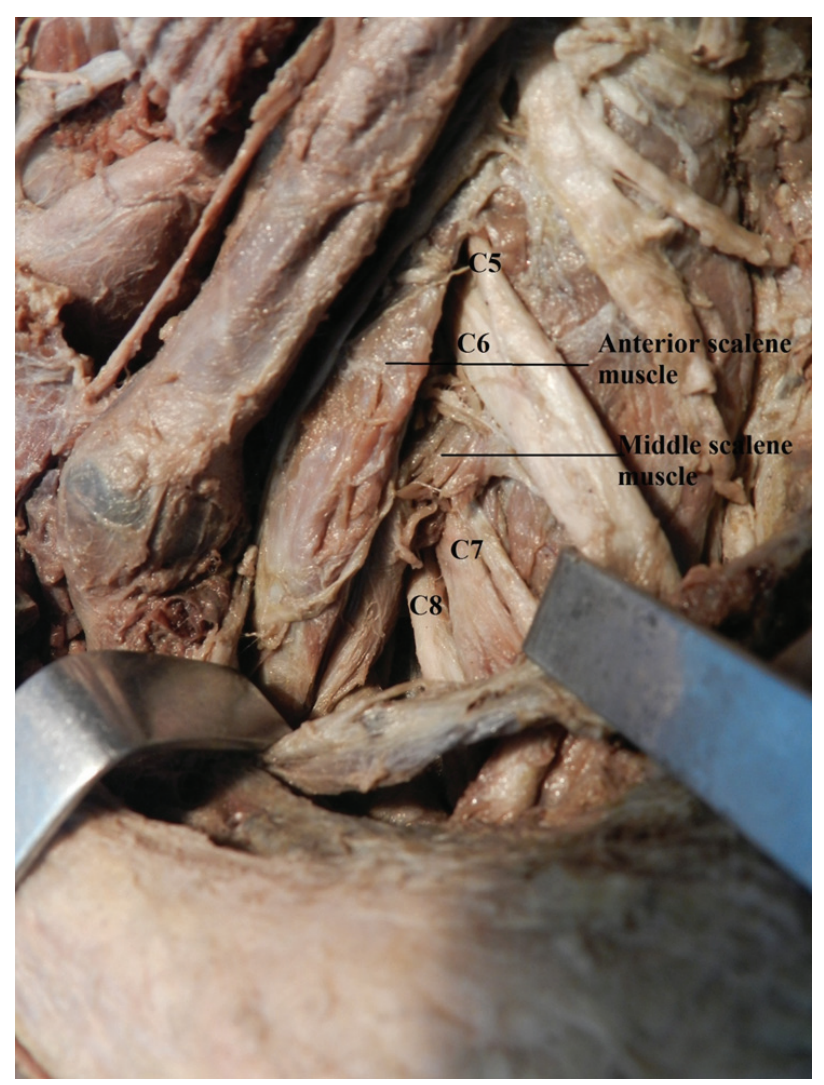

Figure 1. The C7 root is perforating the substance of the middle scalene muscle. middle scalene muscle and in only one of the cadavers the fibers of $\mathrm{C} 7$ were passing into the substance of the middle scalene muscle. This found seems to be like the variation found in our study.

This anatomic variation can implicate in adverse effects in vivo. The nervous root can be attached and compressed in the substance of the middle scalene muscle, especially if this one is hypertrophied, and it can result in a clinic paraparesia in the region of distribution of the nervous fibers of $\mathrm{C} 7$ in the superior limb.

\section{Discussion}

The nervous roots that form the brachial plexus are localized in the posterior triangle of the neck; extend inferiorly, profoundly to the clavicle and under to the posterior venter of the omohyoid muscle. In its trajectory the brachial plexus presents like nervous roots, trunks, fascicules and terminal nervous rams, in this order, forming a complex structure responsible to the innervation of the superior limb (SKANDALAKIS, SKANDALAKIS and SKANDALAKIS, 2007).

The superior and middle trunks of the brachial plexus, when they pass by the lateral border of the anterior scalene muscle, are divided in anterior and posterior divisions. The same occur with the inferior trunk, but just when it pass the first rib, behind the clavicle or the armpit (NARAHASHI, CALDANA, ZONER et al., 2005).

Anatomic variations in the roots, trunks and fascicules of the brachial plexus are common. In accord with Oliveira Filho, Araújo and Queiroz (2009), variant structures have a prevalence of $48 \%$ in diverse populations. Diseases that involve the brachial plexus are common and its anesthesia obloquie is more frequently utilized in the medical practice. This fact justifies the necessity of more studies and knowledge about the issue (OLIVEIRA FILHO, ARAUJO and QUEIROZ, 2009).

According to the literature, two of the principal variations already described are the pre-fixation or the post-fixation of the brachial plexus, when $\mathrm{C} 4$ or $\mathrm{T} 2$ are part of the plexus formation. Fazan, Amadeus and Caleffi (2003) described a rare situation where the nervous roots of $\mathrm{C} 5$ and $\mathrm{C} 6$ fork in an anterior division and in a posterior division, originating in the end of the two superior trunks. Variations of the formation of the trunks involving the nervous roots are reported frequently. Shetty, Satheesha and Madahv (2011) reported the middle trunk being formed by the union of $\mathrm{C} 7$ and C8 and the inferior trunk being formed by the nervous root of $\mathrm{Tl}$ in $2,27 \%$ of the cases. The fusion of the superior trunk and the middle trunk in the posterior triangle of the neck also was described by Shetty, Satheesha and Madahv (2011). Matejcik (2003) reported a case of bilateral fusion of the superior trunk and the middle trunk. In a study achieved by Uysal, Seker and Karabulut (2003) the superior trunk wasn't formed and in $1 \%$ of the cases and the inferior trunk wasn't formed in $9 \%$ of the cases.

The descriptions of Harry, Bennet and Guha (1997) were approximately like the variation found in our study. In their dissections, they observed the nervous roots of $\mathrm{C} 5$ and C6 perforating the substance of the anterior scalene muscle in $15 \%$ of the sides of the necks. They also found a big variation in the position of the root of $\mathrm{C} 5$, with a totally anterior localization in relation with the anterior scalene muscle in $3 \%$ of the sides of the necks. Despite the most of 
the anatomic variations of the brachial plexus in its relations with the scalene muscles evolve the anterior scalene muscle, we observed in $3 \%$ of the sides of the 102 dissected necks one or two nervous roots localized posteriorly to the middle scalene muscle.

The occurrence of compression of nervous structures of the brachial plexus has a relation with the Neurogenic Thoracic Outlet Syndrome. In accord with Harry, Bennet and Guha (1997), there aren't concrete anatomic causes to this syndrome. The more cited causes are the presence of a cervical rib, the presence of the minimum scalene muscle (in addition to the anterior, middle and posterior scalene muscles already mentioned) and variations in the relation of the scalene muscles with the neurovascular structures of the region, situation of the present study. All of these reasons explain the basic characteristic of the syndrome: insufficient space to the passage of neurovascular structures of the region, causing its compression (HARRY, BENNET and GUHA, 1997).

The Neurogenic Thoracic Outlet Syndrome is characterized by the involvement of the subclavian vessels and or of brachial plexus, in the called region of inter-scalene triangle. This region is limited anteriorly by the anterior scalene muscle, posteriorly by the middle scalene muscle and inferiorly by the first rib. Hypertrophies of these muscles and abnormalities of the position of the brachial plexus can cause a nervous or vascular compression of the structures that cross the posterior triangle of the neck, causing the syndrome. The consequences of the Neurogenic Thoracic Outlet Syndrome come from brand symptoms even catastrophic consequences like the atrophy of the hand's muscles and lose of the limb's movements. Necrosis and lose of the fingers and the hand can occur in cases of vascular compression (ATASOY, 2004).

The importance of the brachial plexus variations' study is the fact that this nervous structure is a frequent place of traumatic, inflammatory and neoplastic diseases. In surgeries of the upper limb, the anesthetic blockage of the brachial plexus is necessary and it's performed with the knowledge of the anatomic structures. Then, the knowledge of anatomic variations is important to the management of surgical and anesthetic procedures involving this region. There are related cases of non-well succeeded surgical treatments of the lesions of the brachial plexus in relation with anatomic variations that were neglected (OLIVEIRA FILHO, ARAUJO and QUEIROZ, 2009).

The profound knowledge of the normal or abnormal formation of the brachial plexus has a big utility in diverse other situations, like: to neurosurgeons in the surgical treatments of the nervous sheath's tumors, in the treatment of non-neuronal tumors and in orthopedic procedures of the cervical spine (SHETTY, SATHEESHA and MADAHV, 2011). During surgical procedures the surgeons are exposed to the topographical anatomy of the neural structures and awareness of such variations (DAS and PAUL, 2005).

In a great number of times, when the roots and trunks of the brachial plexus have anatomic variations, these can be found through the ultrasound exams, opening the possibility of to look for variations before the realization of the surgical procedures and, in this way, to plan them in a better form. However, there is the fear of this possibility to make the surgeons and professionals of this area to negate the study and the previous knowledge of the diverse formations of the brachial plexus.

\section{Conclusion}

The variations in the formation of the brachial plexus are very common. In about $50 \%$ of the cases we can find some kind of variation, in its roots, trunks or fascicules. Despite the fact of the most of this variations don't alter the function of the upper limb and its movement, its knowledge is very important to the direct or indirect medical interventions in the upper limb. The variation found by our study can have clinical implications, because the anterior root of $\mathrm{C} 7$ is localized in the interior of the middle scalene muscle, next to its origin. This arrangement can result in motor and sensitive clinical manifestations in the area innervated by $\mathrm{C} 7$.

\section{References}

ACCIOLI, JJV. and ACCIOLI, ZA. Estudo anatômico da abordagem posterior subescapular do plexo braquial. Arquivos Catarinenses de Medicina, 2007, vol. 36, p. 189-193.

ATASOY, E. Thoracic outlet syndrome: anatomy. Hand Clinics, 2004, vol. 20, p. 7-14. http://dx.doi.org/10.1016/ S0749-0712(03)00078-7

DAS, S. and PAUL S. Anomalous branching pattern of lateral cord of brachial plexus. International Journal of Morphology, 2005, vol. 23, n. 4 .

FAZAN, VPS., AMADEUS, AS. and CALEFFI, AL. Brachial plexus variations in its formation and main branches. Acta Cirúrgica Brasileira, 2003, vol. 18, p. 14-18. http://dx.doi.org/10.1590/ S0102-86502003001200006

HARRY, WG., BENNET, JDC. and GUHA, SC. Scalene Muscles and the Brachial Plexus: Anatomical Variations and Their Clinical Significance. Clinical Anatomy, 1997, vol. 10, p. 250-252. http:// dx.doi.org/10.1002/(SICI)1098-2353(1997)10:4<250::AID$\mathrm{CA} 6>3.0 . \mathrm{CO} ; 2-\mathrm{W}$

MATEJCIK, V. Aberrant formation and clinical picture of brachial plexus from the point of view of a neurosurgeon. Bratislavské Lekárske Listy, 2003, vol. 104, n. 10, p. 291-299. PMid:15055727.

MOORE, KL., DALleY, AF. and AGUR, AMR. Anatomia orientada para a clínica. 6. ed. Rio de Janeiro: Guanabara Koogan, 2011.

OLIVEIRA FILHO, J., ARAUJO, VF. and QUEIROZ, RS. Brachial plexus variants: an anatomic study. Revista de Ciências Médicas e Biológicas, 2009, vol. 8, n. 2, p. 142-145.

SHETTY, SD., SATHEESHA, NB. and MADAHV, V. A study on the variations in the formation of the trunks of braquial plexus. International Journal of Morphology, 2011, vol. 29, n. 2, p. 555558. http://dx.doi.org/10.4067/S0717-95022011000200042

SKANDALAKIS, JE., SKANDALAKIS, PN. and SKANDALAKIS, LE. Anatomia e técnica cirúrgica: manual prático. Rio de Janeiro: Revinter, 2007. 662 p.

UYSAL, II., SEKER, M. and KARABULUT, AK. Brachial plexus variations in human fetuses. Neurosurgery, 2003, v. 53, n. 3, p. 676-684. PMid:12943583. http://dx.doi.org/10.1227/01. NEU.0000079485.24016.70

NARAHASHI, E., CALDANA, WCI., ZONER, C., HONDA, E., CAPORRINO, FA., MINE, F., YAMADA, VL., AMARAL, DT., NATOUR, J. and FERNANDES, ARC. Diagnóstico por imagem do Plexo Braquial. Revista Brasileira de Reumatologia, vol. 45, n. 4, p. 245-9, jul./ago. 2005. 